\title{
The structure of ant-plant ecological networks: Is abundance enough?
}

\author{
Wesley Dáttilo, ${ }^{1,3}$ Flavia M. D. Marquitti, ${ }^{2}$ Paulo R. Guimarães, Jr., ${ }^{2}$ and Thiago J. Izzo ${ }^{1}$ \\ ${ }^{1}$ Departamento de Ecologia e Botânica, Laboratório de Ecologia de Comunidades, Universidade Federal de Mato Grosso, \\ Cuiabá, MT, CEP 78060900 Brazil \\ ${ }^{2}$ Departamento de Ecologia, Instituto de Biociências, Universidade de São Paulo, São Paulo, SP, CEP 05508900 Brazil
}

\begin{abstract}
Knowledge of the mechanisms that shape biodiversity is essential to understand the ecological and evolutionary dynamics of interacting species. Recent studies posit that most of the organization of mutualistic networks is shaped by differences in species abundance among interacting species. In this study, we examined the mutualism involving plants with extrafloral nectaries and their associated ants. We show empirically that the difference in abundance among ants on vegetation partially explains the network structure of mutualistic interactions and that it is independent of ant species compositions: an ant species that is abundant usually interacts with more plant species. Moreover, nested networks are generated by simple variation in ant abundance on foliage. However, in ant-plant mutualistic networks, nestedness was higher than in networks describing the occurrence of ants on plants without a food resource. Additionally, the plant and ant species with the highest number of interactions within these networks interacted more among themselves than expected under the assumption of an abundance-based, random mixing of individuals. We hypothesize that the dominance of these ant species occurs because these ants are able to outcompete other ant species when feeding on extrafloral nectaries and because of the presence of ecophysiological adaptations to utilize liquid food.
\end{abstract}

Key words: coevolution; mutualistic networks; nestedness; neutrality; plant-animal interactions.

\section{INTRODUCTION}

A central goal of ecology is to understand the mechanisms that determine the structure of ecological communities at different spatial and temporal scales (Turner 1990, Levin 1992). Recent studies have focused on the structure of ecological networks and have found nonrandom patterns of interaction in a wide range of ecosystems and involving multiple interacting species (Bascompte et al. 2003, Lewinsohn et al. 2006, Guimarães et al. 2007). Several factors have been proposed to explain the origin of structural patterns in ecological networks (reviewed by Vázquez et al. 2009a). One key factor to understand the structure of interaction networks is differences in relative abundance across interacting species (Krishna et al. 2008, Chamberlain et al. 2010, Verdú and Valiente-Banuet. 2011). Abundant species should interact most frequently with each other and with less abundant species, forming a core of highly connected species. In contrast, less abundant species will rarely interact among themselves. As a consequence, it has been hypothesized that species abundance (or interaction frequency) sufficiently explains several struc-

Manuscript received 24 September 2012; revised 5 June 2013; accepted 28 June 2013. Corresponding Editor: L. Stone.

${ }^{3}$ Present address: Instituto de Neuroetología, Universidad Veracruzana, Xalapa, VZ, CP 91190 Mexico.

E-mail: wdattilo@hotmail.com tural aspects of most mutualistic networks, including the observed heterogeneity in the number of interactions per species (Vázquez et al. 2005), asymmetrical patterns of interaction (Vázquez et al. 2007, 2009b) and nestedness (Blüthgen et al. 2008, Krishna et al. 2008).

Inferences on the role of species abundance in shaping network structure are often based on the comparison of the patterns of interaction of an empirical network with the predictions derived from null models. These null models often assume that interaction probabilities are determined by the random mixing of individuals, and their parameterization is based on independent data on species abundance or the use of interaction frequency as a surrogate for species abundance (Vázquez et al. 2007, Blüthgen et al. 2008, Krishna et al. 2008). The null approach provides insight into the role of different factors shaping the patterns of interaction in mutualistic networks. Nevertheless, to understand the role of neutral, abundance-based processes in shaping network structure, one would ideally endeavor to combine evidence derived from null models with a comparison among empirical networks differing in the presence of the crucial resource on which the mutualism is based. Indeed, most mutualisms are based on a key resource, such as nectar and fruits, provided by one of the individuals to attract the partner. However, for most mutualisms, it is impossible to compare empirical mutualistic networks with an empirical benchmark in which the key resource is absent, e.g., recording 
pollinator visitations to plants that are not flowering. However, an exception involves the interactions between plants with extrafloral nectaries (EFNs) and their protective ants.

Interactions between ants and EFN plants are ubiquitous in tropical forests and are well documented as a classical example of mutualism (Rico-Gray and Oliveira 2007). In these associations, plants produce a nutritious liquid to attract ants (Koptur et al. 1998), and, in exchange for food, the ants defend the plants against potential herbivores (Del-Claro et al. 1996, Rico-Gray and Oliveira 2007). Because of ant diversity (Longino et al. 2002) and abundance (up to $94 \%$ of the arthropods and $86 \%$ of the biomass collected in canopies consists of ants [Majer 1990, Tobin 1995]), it is extremely common to observe ants foraging on plants, even in the absence of extrafloral nectar (Andersen 1990, Blüthgen et al. 2000, Davidson et al. 2003). Accordingly, the diversity and abundance of ants create the opportunity to explore the organization of ant-plant interactions in the absence of the key resource for this interaction: the extrafloral nectar. Extrafloral nectar is a predictable, energy-rich resource, and several empirical studies focusing on a few species have demonstrated that different ant species compete to access and dominate such resources (e.g., Blüthgen et al. 2000, Dreisig 2000, Blüthgen and Fiedler 2004a, b). Moreover, only a few ant species possess adaptations for the acquisition, storage, and digestion of liquid resources (Fowler et al. 1991, Oliveira and Brandão 1991, Davidson et al. 2003, 2004), and ants with these traits should have a competitive advantage over species that do not have these adaptations but rather forage on vegetation for prey (Andersen 1990).

Here, we investigate the role of abundance in the shaping multiple networks formed by interactions among ants and EFN plants. In these networks, species are depicted as nodes, and their interactions are depicted by links describing the use of EFN plants by ant species. We compared these ant-plant interaction networks with paired networks describing the occurrence of ants on plants without EFNs. These networks provided a benchmark for studying how interaction networks would be organized if the main resource provided by a mutualistic partner (i.e., EFNs) did not affect the organization of the ant-plant interactions. The resources in plants without EFNs cannot be predicted, and ants forage randomly on plant individuals using the plant only as a substrate (Blüthgen et al. 2000). The presence of ants on such plants may be driven by neutral, nondeterministic factors, such as the available foraging area and species abundance. If specialization and competition for the liquid-energy food source of EFNs were important for structuring ant-plant networks, we would expect differences in the structure of the networks describing the interactions with EFN plants or nonEFN plants. Specifically, we expect that nectar-feeding ants monopolize the resource, interacting with plants more than would be expected from networks of the occurrence of ants on plants that do not offer any predictable type of food resource and forming the core of the highly interactive species observed in these networks.

\section{Materials And Methods \\ Study site and system}

The study was conducted at the São Nicolau Farm $\left(9^{\circ} 48^{\prime} \mathrm{S}\right.$ and $58^{\circ} 15^{\prime} \mathrm{W}$, elevation $\left.254 \mathrm{~m}\right)$ in the municipality of Cotriguaçu, northern Mato Grosso, Brazil. The reserve area covers 7000 ha of continuous forest and is characterized as a tropical rainforest within the southern Brazilian Amazon not subject to seasonal inundation. Canopy trees reach heights of approximately $40 \mathrm{~m}$, with a few emergent canopy trees reaching up $50 \mathrm{~m}$ (Dáttilo et al. 2012). The understory is relatively open and composed mainly by the palm Orbignya phalerata Mart. (Arecaceae). The terrain is moderately undulating, with a maximum elevation difference of approximately $50 \mathrm{~m}$. The region's climate is wet tropical (Am, according to Köppen's climate classification), with annual means of temperature and rainfall of approximately $24^{\circ} \mathrm{C}$ and $2300 \mathrm{~mm}$, respectively (Köppen classification; Camargo et al. 2010), and is divided into two distinct seasons: a November-April rainy season and a May-October dry season.

\section{Data collection}

For sampling, we used a module system managed by the Brazilian Research Program in Biodiversity (PPBio) on São Nicolau Farm. The module is composed of sampling points uniformly distributed in two parallel east-west $5-\mathrm{km}$ trails, $1 \mathrm{~km}$ apart $\left(5 \mathrm{~km}^{2}\right)$. There is one sampling plot of $250 \times 25 \mathrm{~m}\left(6250 \mathrm{~m}^{2}\right)$ every $1 \mathrm{~km}$ along each trail, for a total of 12 sampling points. The central trail in each sampling point has a constant elevation to minimize variations of soil type and elevation (Magnusson et al. 2005). We considered each of the 12 sampling points as an independent sample of ants and plants, generating 12 different ant-plant mutualistic networks and 12 networks that describe the occurrence of ants on plants without EFNs. In the ant-plant mutualistic network, the nodes represent species, and the links depict interactions in which ants are visiting plants with EFNs. In the second set of networks, a link represents the occurrence of a given ant species on a given plant species. We assumed that the ants are sessile organisms (Fourcassié et al. 2003) and that the distance between sampling points was sufficient to guarantee that the organisms of a given plot would never interact with the organisms in another plot. We collected ants and plants in December 2010 and January 2011, always between 09:00 and 15:00. For each of the 12 sampling points, we recorded all the ants collecting nectar from EFN plants that were accessible to the collector (from $0.5 \mathrm{~m}$ to $3 \mathrm{~m}$ high). No plants with homopterous or any other visible liquid-energy resources were included in our sampling. 
We only recorded the interactions between free-living ant species and EFN plants. Furthermore, we did not explore ant-myrmecophyte interactions because these intimate interactions are organized by particular evolutionary and ecological processes that produce different interaction patterns than interactions among ants and EFN plants (Guimarães et al. 2007, Dáttilo 2012).

To minimize the possibility of collecting individuals from the same ant colony foraging on different plants, all the plants recorded within each sampling point were at least $10 \mathrm{~m}$ apart. We used the entomological umbrella method to estimate the interactions in both networks by collecting interacting ants from EFN plants and ants that occurred on plants without EFNs. By sampling both networks in the same way in a paired design, we were able to test the effect of the presence of a resource provided by a mutualistic partner (EFN plants) and lacking in the other network (plants without EFNs). We observed and collected additional ants, particularly more secretive species, before and after performing this procedure to record all the ant species feeding on EFNs. The ant species collected on the EFN plants were always observed feeding on EFNs. Additional details of the sampling procedure can be found in Appendix A.

\section{Species abundance and patterns of interaction}

We used three different approaches to explore the role of abundance in shaping the organization of mutualistic networks of ants and plants with EFNs. First, we evaluated whether differences in abundance among ant species affect the patterns of interaction within the networks of ants and plants with EFNs. We used the records of ants in networks including plants without EFNs as a measure of ant abundance on the vegetation. We assumed that plants without EFNs offer no predictable food resource to the ants and that the frequency of ants on these plants reflects the spatial abundance of these species on the vegetation without the aggregation caused by the attraction to a food resource (Blüthgen et al. 2000). We performed a Spearman correlation to test the hypothesis that the number of interactions increases with the abundance of ant species.

If the difference in abundance is the only factor shaping networks, we should expect that the networks describing the interactions between ants and plants with EFNs would be structurally similar to the networks formed by the occurrence of ants on plants without EFNs. To test this hypothesis, we contrasted the structure of the networks describing interactions between ants and plants with EFNs ( $n=12$ networks) with networks describing the occurrence of ants on plants without EFNs ( $n=12$ networks, forming 12 pairs of networks) and described the difference in the number of species (ants and plants) and the total number of interactions between these two types of networks. We also calculated the following network metrics for each of the networks between ants and plants with and without EFNs: connectance $(C)$, which is the proportion of possible interactions that are actually observed (Jordano 1987), the mean and standard deviation of the number of interactions per plant and ant species, network specialization, modularity, and nestedness. We used these network descriptors because they provide a way to characterize the organization of these networks that allows a direct comparison with the previous work on mutualistic networks. Moreover, both theoretical and empirical evidence associates these metrics with the evolutionary and ecological processes that shape mutualistic networks (Bascompte and Jordano 2007, Blüthgen et al. 2007, Vázquez et al. 2009a, Donatti et al. 2011, Guimarães et al. 2011, Lange et al. 2013).

We calculated the level of specialization in the networks using the quantitative specialization index $\left(H_{2}^{\prime}\right)$, which ranges from 0 (extreme generalization) to 1 (extreme specialization). $H_{2}^{\prime}$ is defined as follows:

$$
H_{2}=-\sum_{i=1}^{P} \sum_{j=1}^{A} p_{i j} \ln p_{i j}
$$

where $i$ represents one plant species and $j$ one ant species, $p_{i j}$ is the proportion of interactions between $i$ and $j, P$ is the plant species richness, and $A$ is the animal species richness

$$
\sum_{i=1}^{P} \sum_{j=1}^{A} p_{i j}=1 .
$$

This index is derived from the Shannon entropy and is based on the deviation from the expected probability distribution of chance interactions (Blüthgen et al. 2006). $H_{2}$ was normalized between the minimum entropy, $H_{2 \min }$, and maximum entropy, $H_{2 \max }$, for associations

$$
H_{2}^{\prime}=\frac{\left(H_{2 \max }-H_{2}\right)}{\left(H_{2 \max }-H_{2 \min }\right)} .
$$

We estimated modularity using the index $M$ (range $0-$ 1), which estimates the degree to which groups of species (ants and plants) interact more with each other than with the species in the other groups in the network (Newman and Girvan 2004, Olesen et al. 2007). The $M$ index is defined as follows:

$$
M=\sum_{s=1}^{N_{\mathrm{m}}}\left[\frac{l_{s}}{L}-\left(\frac{d_{s}}{2 L}\right)^{2}\right]
$$

where $N_{\mathrm{m}}$ is the number of modules, $L$ is the total number of interactions in the network, $l_{s}$ is the number of interactions between the species in module $s$, and $d_{s}$ is the sum of the number of interactions per species of all the species in module $s$ (Olesen et al. 2007). We tested the significance of $M$ for each network through 1000 simulated networks generated by a null model to assess whether the value of $M$ observed in the empirical network was higher than would be expected for networks of equal species richness and similar heterogeneity with regard to interactions among species (null 
model II; Bascompte et al. 2003). Null model II assumes that the probability that plant species $i$ interacts with ant species $j$ depends on the observed number of interactions of both species, such that $P\left(n_{i j}\right)=0.5\left[\left(k_{i} / A\right)+\left(k_{j} / P\right)\right]$, in which $k$ is the number of interactions for the species in the empirical network and $n_{i j}$ is the interaction between ant species $i$ and plant species $j$ in the theoretical network (Bascompte et al. 2003). We constructed each null model network through a routine in MATLAB, and we calculated $M$ using the software Netcarto (Guimerà and Amaral 2005). Although the $M$ index was designed for unipartite networks, our null model controls for the potential effects of a bipartite structure on modularity (i.e., interactions only occur between ant and plant species [Pires et al. 2011]). Because the resource secreted by EFN plants is predictable, we expected that these networks would be more modular because we expect that ants will be more likely to forage on the same plant species.

We used the NODF metric (nestedness metric based on overlap and decreasing fill [Almeida-Neto et al. 2008]) to estimate the nestedness value of the networks using the ANINHADO software (Guimarães and Guimarães 2006). In a nested network, if species $i$ and $j$, both from the same trophic level (plants or ants), differ in their number of interactions $\left(k_{i}<k_{j}\right)$, the set of species interacting with $i$ also interacts with $j$. As a consequence, in nested networks, (1) species with a large number of interactions from different trophic levels tend to interact with each other, forming a core of highly interactive species, (2) species with few interactions tend to interact with highly interactive species, and (3) interactions between species with few interactions rarely occur (Guimarães et al. 2006, Guimarães and Guimarães 2006). Biologically, nestedness describes the organization of niche overlap within interacting assemblages, and species often show high and asymmetrical niche overlaps in a nested network (Bastolla et al. 2009, Blüthgen 2010).

The degree of nestedness may be affected by species richness, connectance, and heterogeneity in the number of interactions. To assess whether the observed nestedness value was higher than would be expected based on these other features of the network structure, we tested the degree of nestedness of each network with 1000 networks generated by the same null model II that we used in the modularity analysis. We then used the ensemble of null model networks to compute $z$ scores for each real network, $z=\left(\mathrm{NODF}_{\mathrm{O}}-\mathrm{NODF}_{\mathrm{T}}\right) / \sigma_{\mathrm{T}}$, in which $\mathrm{NODF}_{\mathrm{O}}$ is the observed value of nestedness for a given real network, $\mathrm{NODF}_{\mathrm{T}}$ is the mean value of nestedness for the null model of our theoretical networks, and $\sigma_{\mathrm{T}}$ is the standard deviation of nestedness values of the ensemble of null model of our theoretical networks. Therefore, these $z$ scores describe the deviation of the degree of nestedness of the real network from the expected nestedness value for networks that share all the attributes observed in the real networks preserved in the null model. Thus, the analysis of nestedness $z$ scores allowed us to investigate whether the patterns observed in the analysis of raw values of nestedness held after controlling for all the network structural patterns preserved by the null model analysis (Almeida-Neto et al. [2008] and Ulrich et al. [2009] for additional details). We used the paired $t$ test (paired per plot) in $\mathrm{R}$ ( $\mathrm{R}$ Development Core Team 2010) to test the difference of all the metrics described in this subsection for the ecological networks of ants and plants with and without EFNs.

Because the ant-plant networks shown here are significantly nested (see Results), we explored the question of whether species abundance affects differently the interactions between highly interactive species (the core of the network) and the interactions between other species in the network (the periphery). We first used a core-periphery analysis (see Diaz-Castelazo et al. [2010] for a similar approach) to identify the core of highly connected species in each network of ants and plants with EFNs. The network core was formed by ant and plant species with $\left(k_{i}-\bar{k}\right) / \sigma_{k}>1$, in which $k_{i}=$ the mean number of interactions for a given plant/ant species, $\bar{k}=$ the mean number of interactions for all plant/ant species in the network, and $\sigma_{k}=$ the standard deviation of the number of interactions for the plant/ant species (Dáttilo et al. 2013a). Accordingly, the periphery was formed by species for which $\left(k_{i}-\bar{k}\right) \sigma / k \leq 1$

If the ant species forming the core of the mutualistic networks were those species with adaptations for the foraging of liquid resources, we should expect only a small subset of ant species to be recorded as core species. We tested this prediction performing a randomization test ( $n=1000$ randomizations). First, we computed the observed core ant species richness, which is the total number of ant species occurring in all 12 ant-EFN-plant networks. We then retained the same number of core and peripheral species in any given ant-EFN-plant network while randomizing the identity of the ant species between groups (core and periphery) and computed the core ant species richness after randomization. Last, we recorded the probability of a given randomization showing a core ant species richness equal to or smaller than that observed in the empirical 12 antEFN-plant networks.

We then computed a probability matrix based on the abundance of interacting species, assuming the random mixing of individuals (Appendix B). We used this matrix to identify the interactions between ants and plants that occurred more frequently than would be expected from the species abundance. We computed the number of interactions showing a frequency that is higher than would be expected based on the species abundance, separately for the core, $E_{\mathrm{c}}$ and the periphery of the network, $E_{\mathrm{p}}$. Because the core and the periphery differ in species richness, we standardized both $E_{\mathrm{c}}$ and $E_{\mathrm{p}}$ by the total number of possible interactions among the core species and among the peripheral species, respectively. 
Using a paired $t$ test, we compared the frequency of interactions that occur more often than would be expected based on the species abundance, between the core species and between the peripheral species in the networks of ants and plants with EFNs.

\section{Additive partitioning of diversity}

To evaluate whether there is a particular assemblage of ant species that forage on EFN plants, we evaluated the turnover of ant species composition ( $\beta$ diversity) between the networks of ants and plants with and without EFNs and calculated the additive partitioning of diversity (Veech et al. 2002). Based on the total ant richness found in each plot ( $\gamma$ diversity), we calculated the $\alpha$ diversity, $\alpha_{\text {mean }}=\left(\alpha_{1}+\alpha_{2}\right) / 2$, where $\alpha_{1}$ is the ant richness in the networks of EFN plants found in the plot and $\alpha_{2}$ is the ant richness in the networks of non-EFN plants found in the plot. We then calculated the $\beta$ diversity as $\beta=\gamma-\alpha_{\text {mean. }}$. Additionally, to evaluate whether the presence of EFNs caused an increase in ant species richness, we randomized ( $n=1000$ randomizations) the plant classification (presence or absence of EFNs) while keeping the $\gamma$ diversity fixed. At the end of each randomization, we counted the ant richness in the networks of EFN plants $\left(\alpha_{1}\right)$ and plants without EFNs $\left(\alpha_{2}\right)$ to assess whether the ant richness in the networks of EFN plants was higher than would be expected for the ant richness in the networks of plants without EFNs. We conducted the randomization through a routine in MATLAB. In addition, to summarize the composition of the ant community on plants with and without EFNs, we ordered the similarity between the points using nonmetric multidimensional scaling (NMDS) and tested the difference in the ant species composition through a permutation test (10000 permutations) based on an analysis of similarities (ANOSIM; Appendix C).

\section{RESULTS}

We recorded 238 plant species (72 EFN plants) and 149 ant species. The number of EFN plant species was lower $(21.4 \pm 3.77[$ mean $\pm \mathrm{SD}])$ than the number of plants without EFNs $(27.2 \pm 3.97, t=-3.093, P=0.011$, $\mathrm{df}=11$ in all analyses). In contrast, the number of ant species on EFN plants $(23.2 \pm 5.85)$ did not differ from the number on plants without EFNs $(23.3 \pm 4.11, t=$ $-0.0647, P=0.949)$. Similarly, the number of interactions was also similar between the networks of ants and EFN plants $(77.91 \pm 12.58)$ and plants without EFNs (75.58 $\pm 10.46, t=1.239, P=0.241)$. The mean and standard deviation for the number of ant species visiting EFN plants $(3.46 \pm 0.28)$ were higher than for plants without EFNs $(2.69 \pm 0.48, t=-3.876, P=0.003$, Fig. 1A). For ants, the mean and standard deviation of plant species visited per ant species did not differ between the networks of EFN plants $(2.67 \pm 0.14)$ and plants without EFNs $(2.64 \pm 0.10, t=0.258, P=0.801$; Fig. 1B).
We did not find significant differences in specialization between the networks (EFN plants, $0.07 \pm 0.05$; plants without EFNs, $0.07 \pm 0.04 ; t=-0.7, P=0.498$ ). The network connectance for ants and EFN plants was higher $(0.140 \pm 0.03)$ than the connectance for ants and plants without EFNs $(0.109 \pm 0.02, t=-3.528, P=$ 0.005 ; Fig. 1C). The degree of modularity was similar to the degree observed in the null model networks, keeping the heterogeneity of interactions at any sampling point $(P>0.05)$. The modularity in the networks of ants and EFN plants $(0.459 \pm 0.059)$ was lower than in the networks of ants and plants without EFNs (0.519 \pm $0.061, t=3.552, P=0.005$, Fig. 1D). Nestedness was higher in the networks of ants and EFN plants (21.01 \pm 4.46) than in the networks of ants and plants without EFNs (15.75 $\pm 3.33, t=-3.427, P=0.006$, Fig. 1E). The same pattern held using the $z$ score estimates of nestedness to control for the effects of species richness and heterogeneity in the number of interactions ( $z$ scores of nestedness in networks of ants and EFN plants, 3.63 \pm 1.51 , and for networks of ants and plants without EFNs, $2.34 \pm 1.35 ; t=-2.270, P=0.04$; Fig. 1 F).

The number of interactions of ant species with EFN plants was associated with ant abundance at all sampling points (Spearman's rho $=0.59 \pm 0.19$, all $P$ $<0.05)$, and the core-periphery analysis showed that one to three $(2.41 \pm 0.66)$ species of ants were present in the generalist core of each network. In fact, of the 149 ant species recorded, only 10 species were present in the core of highly interactive species in at least one network of ants and EFN plants (expected core ant species richness $=21.09 \pm 1.77, P<0.001)$. These recurrent core species have adaptations to utilize a liquid diet and are members of the genera Azteca, Brachymyrmex, Camponotus, Crematogaster (see Plate 1), and Dolichoderus. In addition, on average, most of the interactions between the highly interactive species of ants and plants that formed the core of the network occurred more frequently than would be expected from their abundance $(81.9 \% \pm 19.4 \%$ of all possible interactions; Fig. 2). In contrast, the less connected species of the network interacted less than would be expected from their abundance $(8.7 \% \pm 1.5 \%$ of all possible interactions, $t$ $=-13.28, P<0.0001$; Fig. 2).

The $\beta$ diversity turnover in the ant species composition between the paired networks of ant and plant species with and without EFNs involved approximately one-third of the total diversity and was similar across all plots (Fig. 3). The turnover in ant species composition was reproduced by simulations in which the plant classification (i.e., presence or absence of EFNs) was randomized between the pairs of networks $(P>0.05$ for all plots). Furthermore, the presence of EFNs did not trigger an increase in ant $\alpha$ diversity $(t=1.448, P=$ $0.176)$. An additional NMDS ordination of the ant community showed a similar composition for the networks formed by ants and EFN plants and for the 

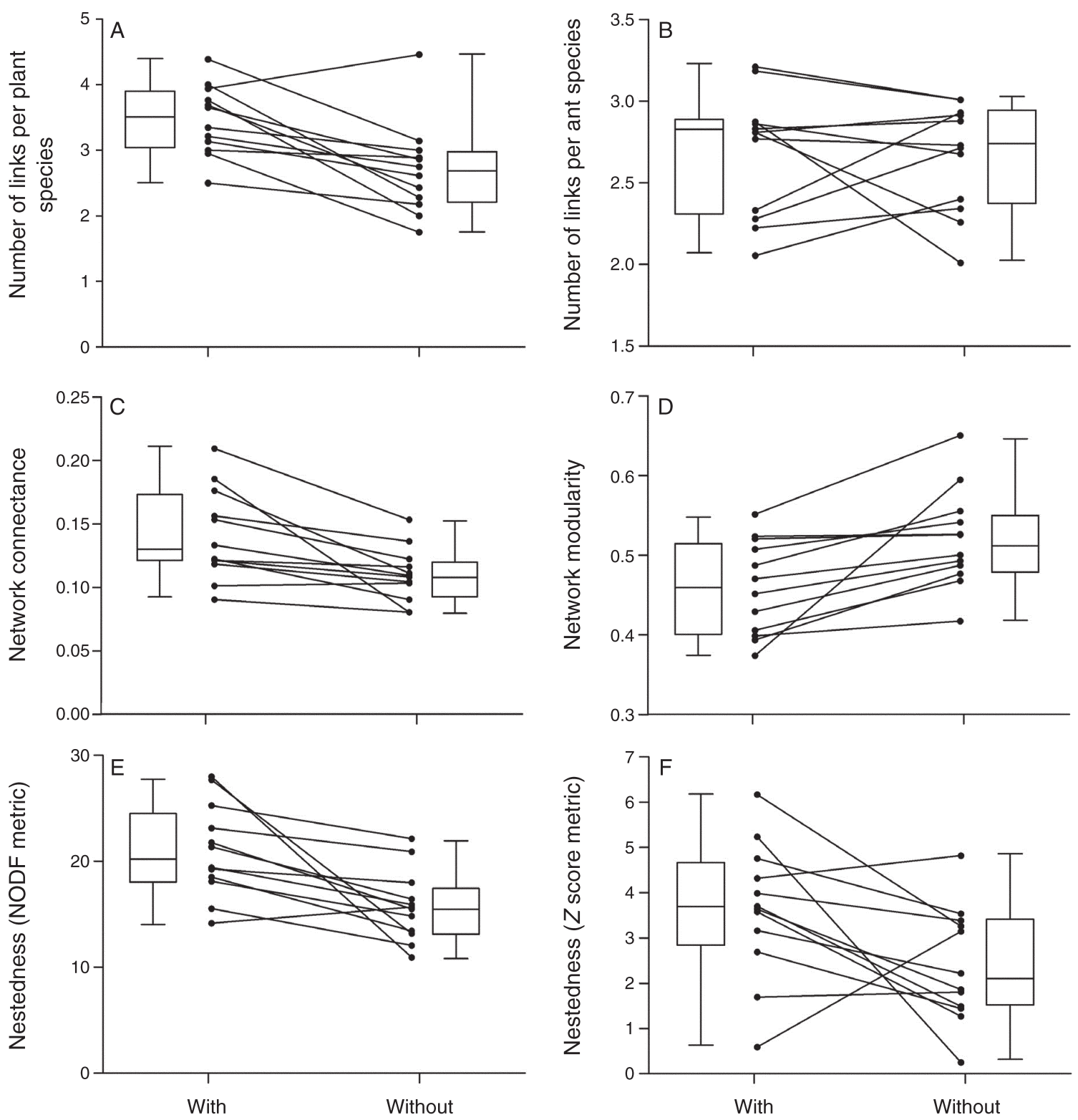

EFN networks

EFN networks

FIG. 1. Relationship for the different metrics used in ecological networks of ants and plants with and without extrafloral nectaries (EFNs): (A) mean number of interactions per plant species, (B) mean number of interactions per ant species, (C) connectance, (D) modularity (none of the plots showed a modularity that was significantly higher than expected from the heterogeneity of interactions), (E) nestedness (NODF metric), and (F) nestedness ( $Z$ score metric). Each line represents one of the 12 paired plots. The data are presented as box plots illustrating the median (center line), quartile (box edges), and extreme values (bars) of each group. Only the mean number of interactions per ant species (B) was not significant (paired $t$ test, $t=0.258, \mathrm{df}=11, P$ $=0.801)$.

networks formed by ants and plants without EFNs (ANOSIM; $P=0.999$, see Appendix C).

\section{DisCUSSION}

Recent studies have shown that relative species abundance is a main driver in structuring mutualistic networks (Vázquez et al. 2007, 2009b, Krishna et al. 2008, Verdú and Valiente-Banuet 2011). These studies have found that the nested and asymmetrical interactions among species within mutualistic networks are often reproduced by null models parameterized with information on species abundance. In the present study, by combining null model analyses with a novel approach in which replicated pairs of mutualistic networks and networks generated by sampling the abundance of ants foraging on plants without EFNs, we were able to 

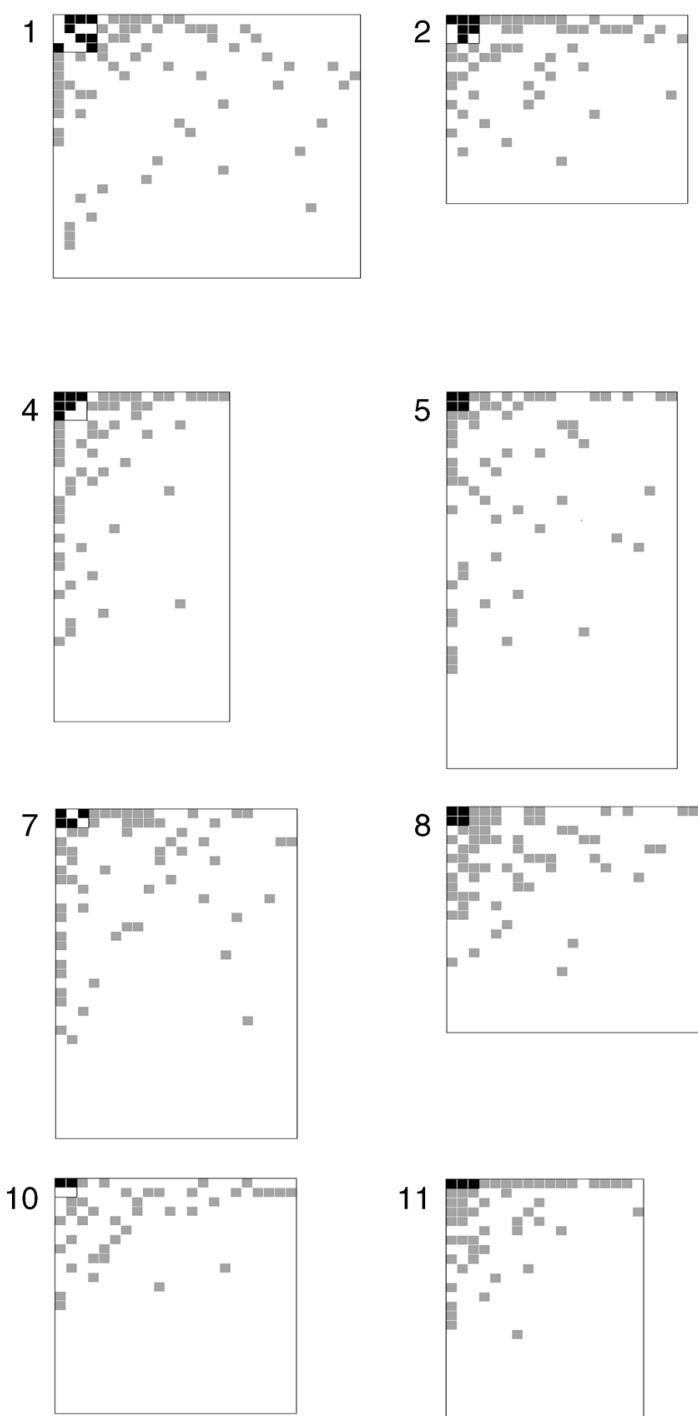

5

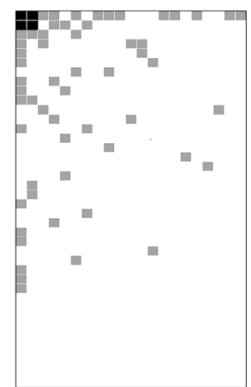

8

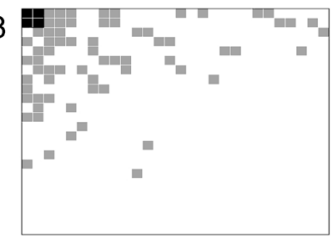

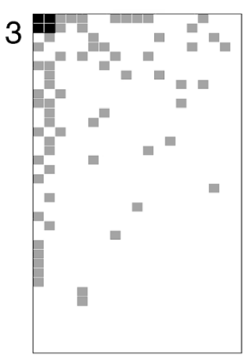
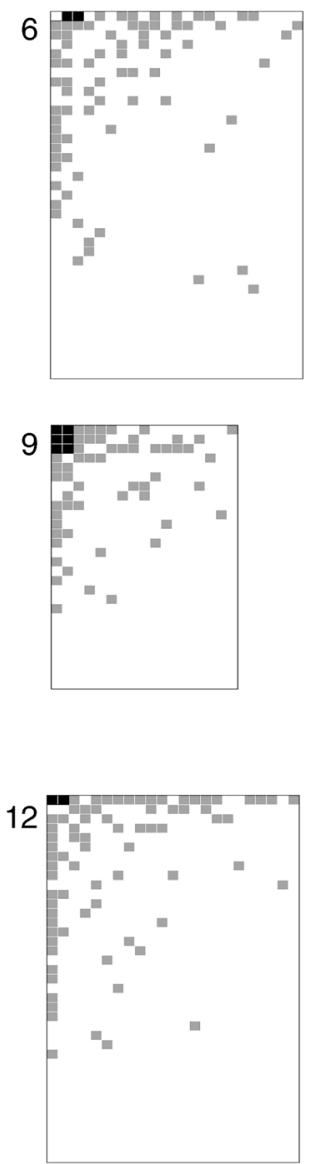

FIG. 2. The 12 interaction matrices between ants and plants with extrafloral nectaries (EFNs). The rows represent the ants, and the columns represent the plants. The numbers above each network represent the plot studied. Cells represent interactions $(i)$ involving core species and occurring in a frequency higher expected by their abundances (black), involving peripheral species and occurring in a frequency higher than expected by their abundances (gray), or occurring in a frequency lower than expected by their abundances (white, including species that did not interact).

untangle three aspects of the network organization of ant-plant interactions.

First, we corroborated the notion that abundance is a key factor organizing mutualistic networks: more abundant ant species often interacts with more EFN plant species. Similar patterns were observed in other mutualisms, such as plant-frugivore interactions (Jordano 1987), pollination networks (Vázquez et al. 2007, Blüthgen et al. 2008), and ant-plant networks in other environments (Chamberlain et al. 2010). More importantly, even networks describing the occurrence of ants on plants without any type of predictable resource show some degree of nestedness (Dáttilo et al. 2013b), providing empirical evidence for the theoretical predictions derived from null models based on neutral theory (Krishna et al. 2008) and probabilistic matrices (Fischer and Lindenmayer 2002, Vázquez et al. 2007, Blüthgen et al. 2008, Blüthgen 2010) that nestedness is expected solely by a neutral, abundance-based mixture of individuals.

Second, the information on the difference in abundance among interacting species was insufficient to 


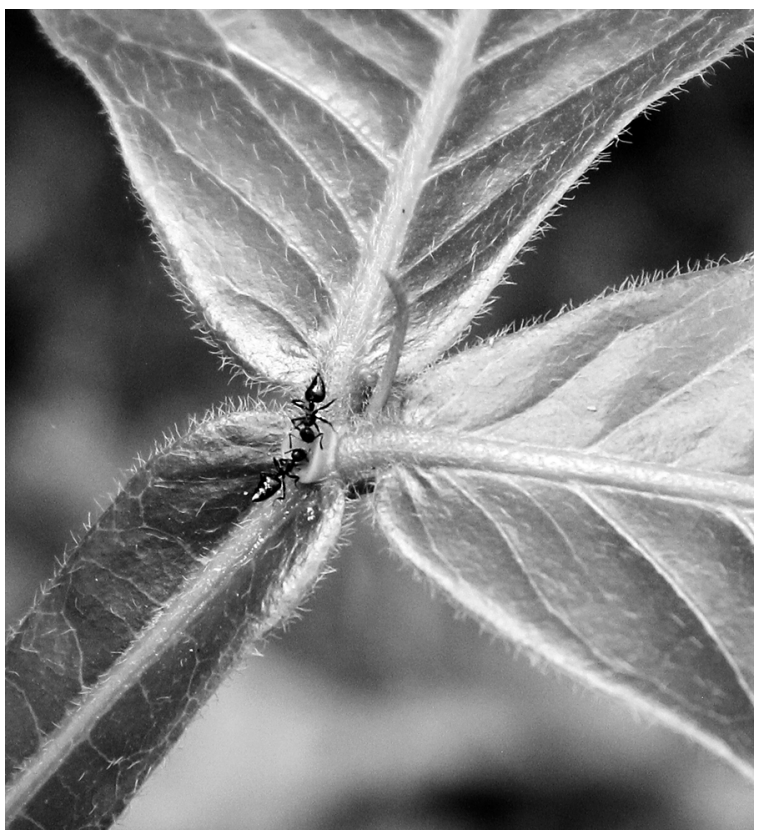

Plate 1. Workers of Crematogaster sp. (Myrmicinae) feeding on an extrafloral nectar of Inga sp. (Mimosaceae). Photo credit: W. Dáttilo.

explain ant-plant network organization. Nestedness in networks of ants and EFN plants was higher than that observed in networks of ants and plants without EFNs. An analysis of $z$ score estimates of nestedness suggested that these differences between networks involving plants with and without EFNs hold after controlling for the effects of species richness, connectance and heterogeneity of interactions. Furthermore, highly connected species interacted more with other species than would be expected from the random mixing of individuals based on their relative abundance. Therefore, the structure of the mutualistic ant-plant interactions found in this study is different from that observed for the natural distribution of ants foraging on plants that do not have EFNs and cannot be simply associated with differences in species abundance.

Third, we showed that only a small subset of component species form the highly interactive core of ant-plant networks, and we hypothesize that this result documents the role of traits in shaping the organization of mutualistic networks. In mutualisms, a dependence on the resource provided by the mutualistic partner (Krishna et al. 2008), trait matching (Stang et al. 2006) and animal size (Chamberlain et al. 2010) also affect the network organization, generating departures from the expected results based on models parameterized with information on species abundance. We proposed two, non-mutually exclusive hypotheses to explain why antplant networks are characterized by a core of highly interactive ant species that represent a small subset of ant species richness.

If EFN plants within the core are the optimal resource, optimal foraging theory predicts that competitively superior ant species would monopolize these plants, whereas less competitive ants would be forced to use suboptimal resources. In fact, competition has been identified as an important factor structuring ant communities (López et al. 1994, Chesson 2000, Parr et al. 2005). Moreover, the quantity and quality of nectar vary among plant species and individuals (Schupp and Feener 1991, Heil et al. 2000). Thus, we hypothesize that the core of highly connected species might be formed by competitively superior ant species that can exclude others, as is expected in ant mosaics in forest canopies (Leston 1978). This hypothesis led to two predictions that future studies should investigate: (1) core plant species have better resources and (2) competitively superior ant species (i.e., by massive recruitment and/ or aggressive behavior) monopolize these more-valuable resources (Heil and McKey 2003, Blüthgen and Fiedler $2004 a, b$ ). In fact, the workers of the core ant species in this study are from Azteca, Brachymyrmex, Camponotus, Crematogaster, and Dolichoderus, which are known to typically exhibit massive recruitment, allowing these $\alpha$ diversity $\quad \beta$ diversity

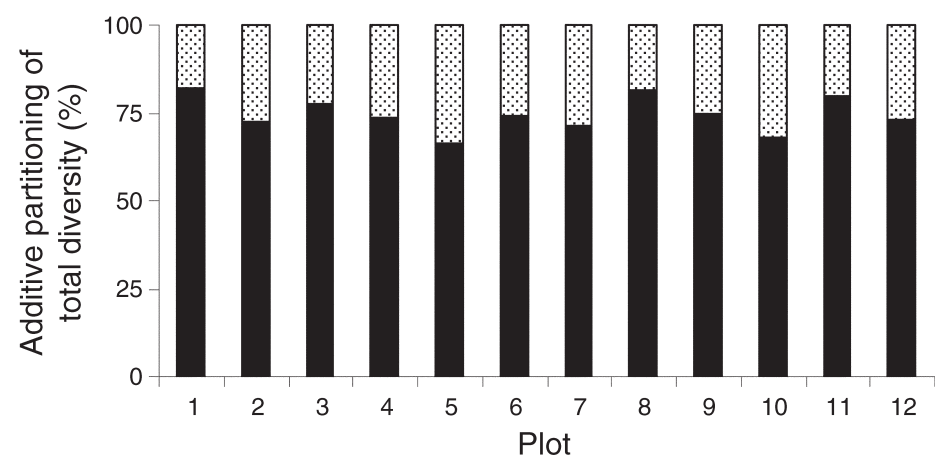

FIG. 3. Percentage of additive partitioning of total diversity of ants collected on plants with and without extrafloral nectaries in 12 plots of a dense terra firme rainforest in the southern Brazilian Amazon. For each plot, the bars represent the observed diversity values. The $\alpha$ diversity represents the mean richness of ants collected on plants with and without extrafloral nectaries (EFNs); $\beta$ diversity represents the turnover of ant species composition collected on plants with and without EFNs in the plots. The total ant richness in both networks was determined by $\gamma$ diversity. The values for the additive partitioning of expected diversity were calculated excluding the effect of the presence of EFNs through 1000 randomizations of plant classification (presence or absence of EFNs). 
ants to dominate the resources and to outnumber other ants when using the resources.

An alternative and not mutually exclusive hypothesis is that this core of highly connected species might be the result of adaptations of a few species related to the exploitation of extrafloral nectar as a resource. The few component species of the core of ant-plant networks have adaptations for liquid feeding, and all the core ant species are from genera that have adaptations to utilize a liquid diet. The workers of these genera can spend more time feeding on nectar because they can perform oral trophallaxis and ingest a large amount of nectar due to proventricular adaptations and gastric expansion (Davidson et al. 2003, 2004). In addition, the species from these genera are known to have physiological adaptations for the digestion of liquid resources secreted by EFNs (Fowler et al. 1991, Davidson et al. 2003).

It is important to note that, although core ant species often show adaptations for feeding on liquid resources and may be competitively superior to other ant species, we found a low turnover of ant species foraging on plants with and without EFNs (as in Schoereder et al. 2010). In fact, some ant genera that lack adaptations for feeding on liquid resources can carry liquids externally and actively use extrafloral nectar (e.g., Acanthoponera, Ectatomma, Heteroponera, Pachycondyla, Paraponera, and Pseudomyrmex [Oliveira and Brandão 1991, Davidson et al. 2003, 2004]). We hypothesize that competition and/or adaptations affect the identity of the species forming the core and the periphery of the networks of ants and plants with EFNs, leading to less specialized ants and weak competitors to participate in these networks as mostly peripheral species.

One theoretical consequence of a core that is formed by species with adaptations to use EFNs, as studied here, is that these adaptations increase the potential for the coevolutionary convergence of traits among species from both sides of the interaction within the community (Bascompte et al. 2003, Thompson 2005, Guimarães et al. 2007). The low variability we observed in the ant core composition suggests a stable network core, as originally proposed by Bascompte et al. (2003). The stability of a highly connected core is predicted by coevolutionary theory (Thompson 2005), is observed in long-term studies in other mutualisms (Olesen et al. 2011, Fang and Huang 2012) and is corroborated by the niche conservatism found across ecological networks (Stouffer et al. 2012), specifically for highly connected species within ant-plant networks (Sugiura 2010, Dáttilo et al. 2013a, Lange et al. 2013). Future empirical studies evaluating the consequences of spatial and temporal variations in ant-plant interactions and other types of mutualistic networks must give particular attention to the network core composition due to its implications for the ecological and evolutionary relationships of communities. Moreover, modeling approaches could be useful to investigate the implications of variations in the species composition of network cores for coevolutionary dynamics.

\section{ACKNOWLEDGMENTS}

We are grateful to Mário Almeida-Neto, Víctor Rico-Gray, Dilermando Lima, Jr., Rogério Silva, Scott Chamberlain, and Mariano Devoto for valuable comments and discussions on earlier versions of the manuscript. We thank Jéssica Falcão for her help during the fieldwork. We also thank ONF-Brazil and the PPBio project for logistical and financial support and the staff of the Central Herbarium of UFMT for identification of plant specimens. W. Dáttilo is grateful for financial support from the CNPq (237339/2012-9) and CONACYT (489746). F. M. D. Marquitti was supported by the grant 2011// 11346-0 and 2012/05935-5, from the São Paulo Research Foundation (FAPESP). P. R. Guimarães was supported by the grant 2009/54422-8, from the São Paulo Research Foundation (FAPESP). This is publication 30 in the NEBAM technical series.

\section{Literature Cited}

Almeida-Neto, M., P. R. Guimarães, Jr., P. Guimarães, R. D. Loyola, and W. Urlich. 2008. A consistent metric for nestedness analysis in ecological systems: reconciling concept and measurement. Oikos 117:1227-1239.

Andersen, A. N. 1990. The use of ant communities to evaluate change in Australian terrestrial ecosystems: a review and a recipe. Proceedings of the Entomological Society of Australia 16:347-357.

Bascompte, J., and P. Jordano. 2007. The structure of plantanimal mutualistic networks: the architecture of biodiversity. Annual Review of Ecology, Evolution, and Systematics 38: 567-593.

Bascompte, J., P. Jordano, C. J. Melián, and J. M. Olesen. 2003. The nested assembly of plant-animal mutualistic networks. Proceedings of the National Academy of Sciences USA 100:9383-9387.

Bastolla, U., M. A. Fortuna, A. Pascual-García, A. Ferrera, B. Luque, and J. Bascompte. 2009. The architecture of mutualistic networks minimizes competition and increases biodiversity. Nature 458:1018-1021.

Blüthgen, N. 2010. Why network analysis is often disconnected from community ecology: a critique and an ecologist's guide. Basic and Applied Ecology 11:185-195.

Blüthgen, N., and K. Fiedler. 2004a. Competition for composition: lessons from nectar-feeding ant communities. Ecology 85:1479-1485.

Blüthgen, N., and K. Fiedler. 2004b. Preferences for sugars and amino acids and their conditionality in a diverse nectarfeeding ant community. Journal of Animal Ecology 73:155166.

Blüthgen, N., J. Fründ, D. P. Vázquez, and F. Menzel. 2008. What do interaction network metrics tell us about specialization and biological traits? Ecology 89:3387-3399.

Blüthgen, N., F. Menzel, and N. Blüthgen. 2006. Measuring specialization in species interaction networks. BMC Ecology 6:12-18.

Blüthgen, N., F. Menzel, T. Hovestadt, B. Fiala, and N. Blüthgen. 2007. Specialization, constraints and conflicting interests in mutualistic networks. Current Biology 17:1-6.

Blüthgen, N., M. Verhaagh, W. Goitía, K. Jaffé, W. Morawetz, and W. Barthlott. 2000. How plants shape the ant community in the Amazonian rainforest canopy: the key role of extrafloral nectaries and homopteran honeydew. Oecologia 125:229-240.

Camargo, F. F., R. B. Costa, M. D. V. Resende, R. A. R. Roa, N. B. Rodrigues, L. V. Santos, and A. C. A. Freitas. 2010. Variabilidade genética para caracteres morfométricos de matrizes de castanha-do-brasil da Amazônia Mato-grossense. Acta Amazonica 40:705-710. 
Chamberlain, S. A., J. R. Kilpatrick, and J. N. Holland. 2010 Do extrafloral nectar resources, species abundances, and body sizes contribute to the structure of ant-plant mutualistic networks? Oecologia 164:741-750.

Chesson, P. 2000. Mechanisms of maintenance of species diversity. Annual Review of Ecology, Evolution, and Systematics 31:343-366.

Dáttilo, W. 2012. Different tolerances of symbiotic and nonsymbiotic ant-plant networks to species extinctions. Network Biology 2:127-138.

Dáttilo, W., P. R. Guimarães, and T. J. Izzo. 2013a. Spatial structure of ant-plant mutualistic networks. Oikos 122:16431648.

Dáttilo, W., R. L. Martins, V. Uhde, J. C. Noronha, F. P. Florêncio, and T. J. Izzo. 2012. Floral resource partitioning by ants and bees in a jambolan Syzygium jambolanum (Myrtaceae) agroforestry system in Brazilian Meridional Amazon. Agroforestry Systems 85:105-111.

Dáttilo, W., V. Rico-Gray, D. J. Rodrigues, and T. J. Izzo. $2013 b$. Soil and vegetation features determine the nested pattern of ant-plant networks in a tropical rainforest. Ecological Entomology 38:374-380.

Davidson, D. W., S. C. Cook, and R. R. Snelling. 2004. Liquid feeding performances of ants (Formicidae): ecological and evolutionary implications. Oecologia 139:255-266.

Davidson, D. W., S. C. Cook, R. R. Snelling, and T. H. Chua. 2003. Explaining the abundance of ants in lowland tropical rainforest canopies. Science 300:969-972.

Del-Claro, K., V. Berto, and W. Réu. 1996. Effect of herbivore deterrence by ants increase fruit set in an extrafloral nectary plant Qualea multiflora (Vochysiaceae). Journal of Tropical Ecology 12:887-892.

Díaz-Castelazo, C., P. R. Guimarães, P. Jordano, J. N. Thompson, R. J. Marquis, and V. Rico-Gray. 2010. Changes of a mutualistic network over time: reanalysis over a 10 -year period. Ecology 91:793-801.

Donatti, C. I., P. R. Guimarães, M. Galetti, M. A. Pizo, F. M. D. Marquitti, and R. Dirzo. 2011. Analysis of a hyperdiverse seed dispersal network: modularity and underlying mechanisms. Ecology Letters 14:773-781.

Dreisig, H. 2000. Defense by exploitation in the Florida carpenter ant, Camponotus floridanus, at an extrafloral nectar resource. Behavioral Ecology Sociobiology 47:274-279.

Fang, Q., and S. Q. Huang. 2012. Relative stability of core groups in pollination networks in a biodiversity hotspot over four years. PLoS ONE 7:e32663.

Fischer, J., and D. Lindenmayer. 2002. Treating the nestedness temperature calculator as a black box can lead to false conclusions. Oikos 99:193-199.

Fourcassié, V., C. Bredard, K. Volpatti, and G. Theraulaz. 2003. Dispersion movements in ants: spatial structuring and density-dependent effects. Behavioural Processes 63:33-43.

Fowler, H. G., L. C. Forti, C. R. F. Brandão, J. H. C. Delabie, and H. L. Vasconcelos. 1991. Ecologia nutricional de formigas. Pages 131-223 in A. R. Panizzi and J. R. P. Parra, editors. Ecologia nutricional de insetos e suas implicações no manejo de pragas. Editora Manole, São Paulo, São Paulo, Brazil.

Guimarães, P. R., P. Jordano, and J. N. Thompson. 2011. Evolution and coevolution in mutualistic networks. Ecology Letters 14:877-885.

Guimarães, P. R., V. Rico-Gray, S. F. dos Reis, and J. N. Thompson. 2006. Asymmetries in specialization in ant-plant mutualistic networks. Proceedings of the Royal Society B 273:2041-2047.

Guimarães, P. R., C. Sazima, S. F. Reis, and I. Sazima. 2007. The nested structure of marine cleaning symbiosis: is it like flowers and bees? Biology Letters 3:51-54.

Guimarães, P. R., Jr., and P. R. Guimarães. 2006. Improving the analyses of nestedness for large sets of matrices. Environmental Modelling and Software 21:1512-1513.
Guimerà, R., and L. A. N. Amaral. 2005. Functional cartography of complex metabolic networks. Nature 433: 895-900.

Heil, M., B. Fiala, B. Baumann, and K. E. Linsenmair. 2000. Temporal, spatial and biotic variations in extrafloral nectar secretion by Macaranga tanarius. Functional Ecology 14: 749-757.

Heil, M., and D. McKey. 2003. Protective ant-plant interactions as model systems in ecological and evolutionary research. Annual Review of Ecology, Evolution, and Systematics 34:425-453.

Jordano, P. 1987. Patterns of mutualistic interactions in pollination and seed dispersal: connectance, dependence, and coevolution. American Naturalist 129:657-677.

Koptur, S., V. Rico-Gray, and M. Palacios-Rios. 1998. Ant protection of the nectaried fern Polypodium plebeium in central Mexico. American Journal of Botany 85:736-739.

Krishna, A., P. R. Guimarães, P. Jordano, and J. Bascompte. 2008. A neutral-niche theory of nestedness in mutualistic networks. Oikos 117:1609-1618.

Lange, D., W. Dáttilo, and K. K. Del-Claro. 2013. Influence of extrafloral nectary phenology on ant-plant mutualistic networks in a Neotropical Savanna. Ecological Entomology 38:464-469.

Leston, D. 1978. A neotropical ant mosaic. Annals of the Entomological Society of America 71:649-653.

Levin, S. A. 1992. The problem of pattern and scale in ecology. Ecology 73:1943-1967.

Lewinsohn, T. M., P. I. Prado, P. Jordano, J. Bascompte, and J. M. Olesen. 2006. Structure in plant-animal interaction assemblages. Oikos 113:174-184.

Longino, J. T., J. Coddington, and R. K. Colwell. 2002. The ant fauna of a tropical rain forest: estimating species richness in three different ways. Ecology 83:689-702.

López, F., J. M. Serrano, and F. J. Acosta. 1994. Parallels between the foraging strategies of ants and plants. Trends in Ecology and Evolution 9:150-153.

Magnusson, W. E., A. P. Lima, R. Luizão, F. Luizão, F. R. C. Costa, C. V. Castilho, and V. P. Kinupp. 2005. RAPELD: a modification of the Gentry method for biodiversity surveys in long-term ecological research sites. Biota Neotropica 5:1924.

Majer, J. D. 1990. The abundance and diversity of arboreal ants in northern Australia. Biotropica 22:191-199.

Newman, M. E., and M. Girvan. 2004. Finding and evaluating community structure in networks. Physical Review E 69: 025103.

Olesen, J. M., J. Bascompte, Y. L. Dupont, and P. Jordano. 2007. The modularity of pollination networks. Proceedings of the National Academy of Sciences USA 104:19891-19896.

Olesen, J. M., C. Stefanescu, and A. Traveset. 2011. Strong, long-term temporal dynamics of an ecological network. PLoS ONE 6:e26455.

Oliveira, P. S., and C. R. F. Brandão. 1991. The ant community associated with extrafloral nectaries in the Brazilian cerrado. Pages 198-212 in D. F. Cutler and C. R. Huxley, editors. Antplant interactions. Oxford University Press, Oxford, UK.

Parr, C. L., B. J. Sinclair, A. N. Andersen, K. J. Gaston, and S. L. Chown. 2005. Constraint and competition in assemblages: a cross continental and modeling approach for ants. American Naturalist 165:481-494.

Pires, M. M., P. R. Guimaraes, M. S. Araujo, A. A. Giaretta, J. C. L. Costa, and S. F. dos Reis. 2011. The nested assembly of individual-resource networks. Journal of Animal Ecology 80:893-903.

R Development Core Team. 2010. R: a language and environment for statistical computing. R Foundation for Statistical Computing, Vienna, Austria. www.r-project.org

Rico-Gray, V., and P. S. Oliveira. 2007. The ecology and evolution of ant-plant interactions. University of Chicago Press, Chicago, Illinois, USA 
Schoereder, J. H., T. G. Sobrinho, M. S. Madureira, C. R. Ribas, and P. S. Oliveira. 2010. The arboreal ant community visiting extrafloral nectaries in the Neotropical cerrado savanna. Terrestrial Arthropod Reviews 3:3-27.

Schupp, E. W., and D. H. Feener. 1991. Phylogeny, lifeform, and habitat dependence of ant-defended plants in a Panamanian forest. Pages 175-197 in D. F. Cutler and C. R. Huxley, editors. Ant-plant interactions. Oxford University Press, Oxford, UK.

Stang, M., P. G. L. Klinkhamer, and W. Van der Meijden. 2006. Size constraints and flower abundance determine the number of interactions in a plant-flower visitor web. Oikos 112:111-121.

Stouffer, D. B., M. Sales-Pardo, M. I. Sirer, and J. Bascompte. 2012. Evolutionary conservation of species' roles in food webs. Science 335:1489-1492.

Sugiura, S. 2010. Species interactions-area relationships: biological invasions and network structure in relation to island area. Proceedings of the Royal Society B 277:1807-1815.

Thompson, J. N. 2005. The geographic mosaic of coevolution. University of Chicago Press, Chicago, Illinois, USA.

Tobin, J. E. 1995. Ecology and diversity of tropical forest canopy ants. Pages 129-147 in M. D. Lowman and N. M. Nadkarni, editors. Forest canopies. San Diego Academic Press, San Diego, California, USA.
Turner, M. G. 1990. Spatial and temporal analysis of landscape patterns. Landscape Ecology 4:21-30.

Ulrich, W., M. Almeida-Neto, and N. J. Gotelli. 2009. A consumer's guide to nestedness analysis. Oikos 118:3-17.

Vázquez, D. P., N. Blüthgen, L. Cagnolo, and N. P. Chacoff. 2009 a. Uniting pattern and process in plant-animal mutualistic networks: a review. Annals of Botany 103:1445-1457.

Vázquez, D. P., N. P. Chacoff, and L. Cagnolo. $2009 \mathrm{~b}$. Evaluating multiple determinants of the structure of mutualistic networks. Ecology 90:2039-2046.

Vázquez, D. P., C. J. Melián, N. M. Williams, N. Blüthgen, B. R. Krasnov, and R. Poulin. 2007. Species abundance and asymmetric interaction strength in ecological networks. Oikos 116:1120-1127.

Vázquez, D. P., R. Poulin, B. R. Krasnov, and G. I. Shenbrot. 2005. Species abundance patterns and the distribution of specialization in host-parasite interaction networks. Journal of Animal Ecology 74:946-955.

Veech, J. A., K. S. Summerville, T. O. Crist, and J. C. Gering. 2002. The additive partitioning of species diversity: recent revival of an old idea. Oikos 99:3-9.

Verdú, M., and A. Valiente-Banuet. 2011. The relative contribution of abundance and phylogeny to the structure of plant facilitation networks. Oikos 120:1351-1356.

\section{Supplemental Material}

\section{Appendix A}

Additional sampling procedures of ants and plants in a mature rainforest, São Nicolau Farm, municipality of Cotriguaçu, northern Mato Grosso, Brazil (Ecological Archives E095-042-A1).

\section{Appendix B}

Detailed mathematical procedure used to determine the ants that interact more than expected by their natural abundances (Ecological Archives E095-042-A2).

\section{Appendix C}

Quantitative and qualitative ordinations of ant communities foraging on plants with and without extrafloral nectaries (Ecological Archives E095-042-A3). 